\title{
Distinctive features of severe SARS-CoV-2 pneumonia
}

\author{
G.R. Scott Budinger, Alexander V. Misharin, Karen M. Ridge, Benjamin D. Singer, and Richard G. Wunderink
}

Department of Medicine, Division of Pulmonary and Critical Care Medicine, Northwestern University, Chicago, Illinois, USA.

\begin{abstract}
The coronavirus disease 2019 (COVID-19) pandemic is among the most important public health crises of our generation. Despite the promise of prevention offered by effective vaccines, patients with severe COVID-19 will continue to populate hospitals and intensive care units for the foreseeable future. The most common clinical presentation of severe COVID-19 is hypoxemia and respiratory failure, typical of the acute respiratory distress syndrome (ARDS). Whether the clinical features and pathobiology of severe acute respiratory syndrome coronavirus 2 (SARS-CoV-2) pneumonia differ from those of pneumonia secondary to other pathogens is unclear. This uncertainty has created variability in the application of historically proven therapies for ARDS to patients with COVID-19. We review the available literature and find many similarities between patients with ARDS from pneumonia attributable to SARS-CoV-2 versus other respiratory pathogens. A notable exception is the long duration of illness among patients with COVID-19, which could result from its unique pathobiology. Available data support the use of care pathways and therapies proven effective for patients with ARDS, while pointing to unique features that might be therapeutically targeted for patients with severe SARS-CoV-2 pneumonia.
\end{abstract}

\section{Introduction}

A small fraction of patients infected with severe acute respiratory syndrome coronavirus 2 (SARS-CoV-2), the virus responsible for coronavirus disease 2019 (COVID-19), develop severe disease resulting in death or requiring hospitalization and mechanical ventilation. Public health interventions to reduce virus transmission are primarily designed to prevent these complications. Thus, it is the propensity of SARS-CoV-2 to cause severe disease that has driven the social and economic costs associated with the pandemic to date. Effective vaccines targeting SARS-CoV-2 provide an invaluable public health tool to reduce disease prevalence and severity (1-5). Despite the promise of prevention, patients with severe COVID-19 will likely continue to populate hospitals and intensive care units for the foreseeable future. Perhaps more importantly, we can expect new Betacoronavirus pathogens to emerge, some of which may cause severe disease (6-9). This fact creates an urgent need to understand the pathobiology of SARSCoV-2 infection, focusing on factors that underlie the differential susceptibility to severe disease. Hence, we focus this Review primarily on patients with severe SARS-CoV-2 pneumonia (WHO COVID severity 6-8 [ref. 10] and NIH "severe" and "critical" COVID-19 [ref. 11]). Many of these patients meet the diagnostic criteria for the acute respiratory distress syndrome (ARDS).

The primary clinical and pathologic features of severe COVID-19 are attributable to SARS-CoV-2 infection of the lung (pneumonia). Pneumonia was the leading cause of death from an infectious disease before the pandemic (12), and patients with pneumonia or aspiration comprised more than half the patients in well-defined cohorts of patients with ARDS (13). Also before

Conflict of interest: BDS holds US patent 10,905,706, "Compositions and methods to accelerate resolution of acute lung inflammation."

Copyright: (c) 2021, American Society for Clinical Investigation.

Reference information: J Clin Invest. 2021;131(14):e149412.

https://doi.org/10.1172/JCl149412. the pandemic, respiratory viruses, including influenza viruses, were identified as the most common cause of communityacquired pneumonia among adults requiring hospitalization (14). Hence, we start our analysis from the null hypothesis that SARSCoV-2 pneumonia and the clinical features of COVID-19 do not differ from severe community-acquired pneumonia caused by other respiratory viruses resulting in ARDS. We review the state of the science, examining the similarities and differences among patients with pneumonia due to SARS-CoV-2 versus other pathogens, particularly influenza.

\section{Similarities in pneumonia secondary to SARS- CoV-2 versus other respiratory pathogens}

In late 2019, reports emerged from Wuhan, China, of a severe respiratory syndrome complicated by multiple organ dysfunction that was often fatal (15-21). Shortly thereafter, the genetic sequence of the novel Betacoronavirus causing this syndrome was published (22). Before the virus was formally named SARS-CoV-2 (23) and before the lack of tropism of the virus for organs outside the respiratory system was known, the World Health Organization coined the term "coronavirus disease 2019" (COVID-19) to describe the clinical syndrome.

The initial case descriptions from Wuhan emphasized the importance of pulmonary infection; however, a plethora of case reports early in the pandemic focused on extrapulmonary complications of the disease. Within the same window of time, several groups reported leukocytosis, lymphopenia, and elevated levels of inflammatory cytokines in convenience blood samples from patients with severe COVID-19 (24-27). Importantly, none of these early studies included control groups of similarly ill patients with pneumonia secondary to other pathogens. Instead, healthy individuals or patients with mild disease were compared with patients with severe disease. Furthermore, few studies included bronchoalveolar lavage or other respiratory samples commonly used in the care and study of patients with ARDS because of 
concerns about generating infectious aerosols (28). As a result, COVID-19 was increasingly seen as a clinical syndrome caused by "immune dysregulation" and "cytokine storm" rather than severe SARS-CoV-2 pneumonia leading to ARDS, and care pathways and treatments began to diverge from those used historically to treat severe viral pneumonia $(29,30)$.

As with other respiratory viruses, the clinical severity of SARS-CoV-2 infection varies dramatically between patients. The NIH classifies COVID-19 severity according to five categories: asymptomatic, mild, moderate, severe, and critical (11). The vast majority of patients develop asymptomatic, mild, or moderate illness and are usually managed at home without oxygen therapy (31-37). Patients with severe illness are characterized by arterial hypoxemia and respiratory distress similar to that seen in patients with evolving ARDS. Patients with critical illness develop respiratory failure, septic shock, and/or multiple organ dysfunction. In a series of 44,672 patients with confirmed symptomatic SARSCoV-2 infection in China, $14 \%$ had severe illness and $5 \%$ had critical illness (38).

Severe or critical SARS-CoV-2 pneumonia is characterized by bilateral multifocal pulmonary infiltrates that result in acute hypoxemic respiratory failure, often fulfilling the Berlin criteria for diagnosis of ARDS. These include severe arterial hypoxemia despite supplemental oxygen and bilateral infiltrates on chest imaging that are not solely attributable to cardiac dysfunction (3941). Despite early suggestions that the physiology of ARDS secondary to SARS-CoV-2 pneumonia differs from that induced by other respiratory pathogens $(29,30)$, lung compliance, deficits in oxygenation, responsiveness to positive end-expiratory pressure, and driving pressure in patients with ARDS secondary to SARS-CoV-2 pneumonia are similar to those measured in historical studies of patients with ARDS (41). The severity of illness among patients with severe SARS-CoV-2 pneumonia is similar to that among other critically ill patients with pneumonia as measured by standardized intensive care unit (ICU) predictive tools such as the Sequential Organ Failure Assessment (SOFA) score or the Acute Physiology and Chronic Health Evaluation (APACHE) score (39, 41-44). Early in the pandemic, mortality from severe COVID-19 was over $50 \%$ $(15-20,45)$. It is now clear that these high mortality rates were in part attributable to the rapid and large influx of patients that overwhelmed health care systems (46). In regions where health care systems were not overwhelmed, mortality rates were similar to predicted mortality rates for comparably ill ICU patients $(41,44)$. Collectively, these findings suggest that supportive therapies with proven benefit in patients with ARDS, including the use of highflow nasal cannula oxygen and mechanical ventilation, should be used to treat patients with severe SARS-CoV-2 pneumonia in accordance with standard ICU practice.

Inflammatory biomarkers including IL-6, C-reactive protein, D-dimer, ferritin, and procalcitonin are elevated in patients with severe SARS-CoV-2 pneumonia, and the levels of IL-6 have been shown to predict mortality (47-49). IL6 transcription is not increased in any circulating cell population, suggesting that it is secreted from cells within the lung or other organs (25). Furthermore, the peak levels of IL- 6 are similar in patients with severe SARS-CoV-2 pneumonia and similarly ill control patients $(50,51)$. High levels of the same inflammatory cytokines were associated with severity of illness among patients with community-acquired pneumonia and ARDS secondary to other etiologies before the pandemic (52-55).

Proteomic analysis of peripheral blood samples from patients with severe SARS-CoV-2 pneumonia detects proteins that are normally expressed only in the lung epithelium, including pulmonary surfactants SFTPB and SFTPD, and advanced glycosylation end product-specific receptor (AGER), among others, indicating ongoing pulmonary epithelial injury (56). Some of these markers have been identified in patients with ARDS secondary to other causes (57). In addition, patients with severe SARS-CoV-2 pneumonia often have mild to moderate elevations in circulating markers of nonspecific tissue injury (e.g., lactate dehydrogenase) and tissue-specific injury, including troponin (heart), creatine phosphokinase (skeletal and cardiac muscle), and aspartate aminotransferase and alanine transaminase (liver), that are similar to levels observed with other types of pneumonia $(44,49)$. As most autopsy studies failed to identify SARS-CoV-2 in these tissues, elevations in these molecules likely result from immunemediated tissue injury or microvascular thrombosis and tissue ischemia (58-60). Notably, IL-6 induces the transcription of clotting factors in the liver and tissue factor expression in endothelial cells, monocytes, and other cells that might drive systemic thrombosis to cause tissue injury $(61,62)$.

The cellular composition of the peripheral blood is abnormal in patients with severe SARS-CoV-2 pneumonia (25, 27, 63-67). Abnormalities include lymphopenia and an absolute leukocytosis with an expansion of the circulating neutrophil pool, including the release of immature neutrophils (e.g., bands) from the bone marrow. However, this evidence of emergency myelopoiesis is typical for a broad range of patients with pneumonia and other systemic infections (68). Similarly, lymphopenia has been previously associated with poor outcomes among patients with severe community-acquired pneumonia (69). Studies in which peripheral blood is serially sampled generally show resolution of these abnormalities over the course of the disease. However, it is important to note that high rates of ventilatorassociated pneumonia in patients with SARS-CoV-2 pneumonia (44\% in our cohort) may confound these results (70).

Radiographic abnormalities in the lung detected by chest radiography or CT range from single or multiple small areas of ground-glass infiltrates to multifocal confluent areas of groundglass infiltrates involving most of the lung parenchyma (71). A meta-analysis of studies comparing chest CT findings in patients with SARS-CoV-2 and other viral pneumonia found no differences save a slightly higher prevalence of peripherally distributed ground-glass infiltrates (71). Studies in which asymptomatic individuals with confirmed SARS-CoV-2 infection have undergone chest imaging reveal abnormalities in as many as $50 \%$ of patients, suggesting that distal lung involvement is common even in nonsevere disease $(72,73)$. Whether the finding of distal lung abnormalities in patients with mild or no symptoms is unique to SARSCoV-2 infection is not known.

\section{Distinctive clinical features of SARS-CoV-2 infection}

The clinical course of SARS-CoV-2 pneumonia is longer than that of pneumonia secondary to influenza or bacterial pneumonia. 


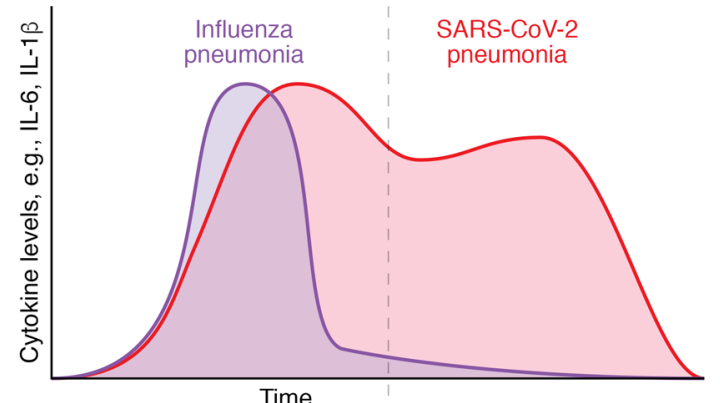

Primary respiratory infection
Secondary organ injury

Elevated creatine kinase

Encephalopathy

Elevated cardiac troponin

Deep venous thrombosis

Elevated alanine aminotransferase,

aspartate aminotransferase

Acute tubular necrosis, glomerular injury
Figure 1. The long clinical course of SARS-CoV-2 pneumonia may contribute to multiple organ dysfunction. The duration of symptoms before the development of respiratory failure and the duration of mechanical ventilation are much longer in patients with SARS-CoV- 2 pneumonia than in those with influenza pneumonia. Although peak circulating levels of inflammatory cytokines are similar among patients with SARS-CoV-2 (pink) and patients with influenza pneumonia (purple), the longer duration of illness increases cumulative cytokine exposure (area under the time-cytokine level curve), which may contribute to the secondary multiple organ dysfunction observed in patients with SARSCoV-2 pneumonia.

The duration of time from the onset of symptoms to the development of severe or critical disease is 9 days (range 6-12 days) among patients with SARS-CoV-2 pneumonia, which is more than double the duration in patients with influenza pneumonia (4 days, range 0-7 days) $(15,17,74-76)$. Similarly, the duration of mechanical ventilation is prolonged among patients with pneumonia and respiratory failure secondary to SARS-CoV-2 compared with other respiratory pathogens (14 days compared with 4 days in our study) (44). Similar long lengths of mechanical ventilation or ICU stay (9-18 days) have been reported by other groups $(18,21,32,33$, 3539). Incomplete or prolonged recovery after SARS-CoV-2 pneumonia has been reported, sometimes requiring lung transplantation as a salvage therapy, but whether these outcomes differ from those of pneumonia secondary to other pathogens is not known (77). As similar levels of IL-6 and other inflammatory cytokines are found in patients with pneumonia attributed to SARS-CoV-2 and other respiratory pathogens, we suggest that prolonged exposure to elevated levels of inflammatory cytokines might underlie some of the immunopathology observed in patients with SARSCoV-2 pneumonia (Figure 1).

Influenza pneumonia causes severe disease and death in both very young and elderly patients $(78,79)$. This U-shaped mortality curve with advancing age in patients with influenza pneumonia contrasts dramatically with the mortality curve of SARS-CoV-2 infection, for which severe pneumonia in children is distinctly unusual (80). Risk factors for developing severe disease or death after infection with SARS-CoV-2 include older age and male sex $(81,82)$. In addition, obesity and other comorbid illnesses, including hypertension and diabetes, have been associated with more severe disease in several cohorts (81-83). Similar associations were reported during the H1N1 influenza A pandemic (84-86).

\section{SARS-CoV-2}

SARS-CoV-2 is a positive-sense singlestranded RNA virus with a genome size much larger than that of influenza A $(\sim 30$ $\mathrm{kb}$ compared with $\sim 14 \mathrm{~kb}$ ) (23). SARS-CoV-2 enters cells by binding a homotrimeric spike protein on the virus surface to ACE2 expressed on target cells in the host (87). After binding, the spike protein is cleaved by host proteases, causing extensive irreversible changes necessary for viral entry and replication. The spike protein binding domain is the target for the three vaccines authorized for emergency use in the United States and most vaccines that are being administered worldwide (1-5). For the related Betacoronavirus SARS-CoV, cleavage of the spike protein requires a specific host protease, TMPRSS2; however, SARSCoV-2 harbors a mutation in the spike protein that encodes a furin cleavage domain, allowing it to be cleaved by a variety of host proteases, possibly dispensing with the requirement for TMPRSS2 (88-90).

SARS-CoV-2 enters the cytosol by membrane fusion, where it is transcribed into two large mRNA fragments, encoding 16 nonstructural proteins, eight accessory proteins, and four structural proteins (87). The nonstructural and accessory proteins globally suppress host cell translation and type I IFN production. Accordingly, type I IFN levels are low in the peripheral blood of patients with severe SARSCoV-2 pneumonia $(24,26,91)$. Whether these levels are lower than those observed in patients with pneumonia secondary to other respiratory viruses is not known. Viral replication and transcription occur in lipid membrane-enclosed structures adjacent to the endoplasmic reticulum generated in response to SARS-CoV-2 infection. Within those structures, a negative-strand RNA species serves as a template for viral replication. The nucleocapsid protein encapsulates the full-length positive-sense viral RNA, after which the envelope, membrane, and spike proteins are recruited, and the virus is released by exocytosis.

The expression of ACE2 in the human respiratory system is sparse and follows a descending gradient along the respiratory tract. RNA encoding ACE2 is detected in approximately $3 \%-4 \%$ of epithelial cells in the nose, less than $1 \%$ of tracheal epithelial cells (mostly in ciliated cells and goblet cells), and less than $1 \%$ of alveolar type 2 cells $(60,92-94)$. Hence, while the exact mechanisms are unknown, SARS-CoV-2 likely reaches the distal lung via droplet aspiration from the nasopharynx or oropharynx (95). The sparse expression of ACE2 contrasts dramatically with expression of the $\alpha 2,6$-linked sialic acid residues that serve as receptors for influenza viruses, which are abundantly expressed on almost all airway and type 2 alveolar epithelial (AT2) cells throughout the respiratory tract and distal lung $(96,97)$. The detection of SARSCoV-2 transcripts in the lung epithelium in patients who died with SARS-CoV-2 pneumonia largely follows the distribution of ACE2 expression $(59,93)$. 


\section{Autopsy findings in patients with severe SARS- CoV-2 pneumonia}

Almost without exception, the primary pathology at autopsy is found in the lungs of patients who died from SARS-CoV-2 pneumonia (58-60, 92, 98). Grossly, the lungs are edematous, heavy, and boggy, often with cystic structures histologically defined as pneumatoceles. In some patients, larger cavitary lesions representing lung abscesses secondary to ventilatorassociated pneumonia are reported. Microscopy reveals spatially restricted regions of diffuse alveolar damage, alveolar hemorrhage, reactive pneumocytes, organizing pneumonia, interstitial fibrosis, bronchiolitis, and bronchiolar fibrosis sometimes interspersed with normal lung. While occasional thrombi are observed in microvessels, evidence of direct vascular infection is infrequently observed (99). Some patients develop fibrosis resembling late-stage idiopathic pulmonary fibrosis (100). None of these features are unique to patients with SARS-CoV-2 pneumonia (101). For example, similar histopathologic features were reported in patients who died from influenza A pneumonia during the 2009 H1N1 pandemic (101, 102). Different types of pathology, ranging from diffuse alveolar damage to organizing pneumonia with fibrosis, are observed within the same lung in patients with SARS-CoV-2 pneumonia. These findings suggest a multifocal process that evolves slowly in spatially restricted areas over time $(103,104)$. As autopsy studies are biased toward patients who died later in the course of the disease, late complications of ICU care, particularly ventilator-associated pneumonia, could obscure early pathologic changes in patients with SARS-CoV-2 pneumonia.

Evidence of prolonged viremia in patients with SARS-CoV-2 pneumonia is lacking. Extensive bulk and single-cell transcriptomic analyses of blood from patients with severe COVID-19 have not revealed evidence of viral transcripts in circulating blood cells (25). Andersson et al. analyzed blood samples from 212 patients with acute and convalescent COVID-19, some of whom required mechanical ventilation. They found that while $12.7 \%$ of peripheral blood samples tested positive for SARSCoV-2 by PCR, no replication-competent virus capable of infecting cultured cells was detected in any of the samples (105). Consistent with a lack of circulating virus capable of tissue infection, vertical transmission of SARS-CoV-2 from virus-positive women to the placenta or fetus is rare (106-108). Additional studies are needed to determine the duration of transmissible virus shedding from lower respiratory tract samples.

Given the lack of replication-competent viremia, the importance of anecdotal reports suggesting detection of SARS-CoV-2 transcripts or protein in a host of tissues outside the lung is unclear. Many of these reports relied on PCR analyses of tissues, which are susceptible to cross-contamination at the time of autopsy and do not necessarily detect replication-competent virus. Antibodies used to detect SARS-CoV-2 proteins have not been rigorously examined for specificity across various tissues. Reports of SARSCoV-2 viral particles detected using electron microscopy have been questioned due to similarities between the virus and normal cellular substructures $(109,110)$. Because SARS-CoV-2 is an RNA virus, single-molecule fluorescence in situ hybridization (sm-FISH) is perhaps the best and most specific method to detect it in tissues. In a systematic sm-FISH autopsy survey of tissues from 32 patients, many of whom had died early in their disease course, investigators found evidence for SARS-CoV-2 in the tracheobronchial or alveolar epithelium and in alveolar macrophages in 20 patients. In one patient, SARS-CoV-2 RNA was detected in endothelial cells adjacent to a thrombus in the lung. SARS-CoV-2 was detected outside the lung in only one patient, where it was found in endothelial cells in multiple tissues (59). In all cases, the concentration of virus (estimated by Ct values using PCR) was substantially higher in the lung compared with other tissues. Similar findings have been reported by others (92). A recent systematic survey of autopsy tissues from patients who died from SARS-CoV-2 pneumonia analyzed using single-cell RNA-Seq and sm-FISH did not detect viral transcripts outside the lung or in endothelial cells in the lung (99). Whether infection of kidney proximal tubular cells or podocytes, which express $A C E 2$, is responsible for the acute kidney injury observed in patients with COVID-19 is controversial (111).

\section{Studies of SARS-CoV-2 pneumonia in patients}

Observational studies of patients with SARS-CoV-2 pneumonia have provided important insights into disease pathobiology, but it is important to acknowledge their limitations. First, most studies compare patients with severe SARS-CoV-2 pneumonia with healthy people or patients with mild SARS-CoV-2 infection. Only a handful of studies enrolled similarly ill patients with pneumonia secondary to other pathogens. Second, while alveolar sampling using bronchoalveolar lavage can be safely performed in mechanically ventilated patients with ARDS to diagnose and guide treatment for ventilator-associated pneumonia (28), many centers curtailed its use in patients with SARS-CoV-2 pneumonia because of concerns about infectious aerosol generation, limiting its availability for clinical care and research. Third, as noted above, severe SARS-CoV-2 infection in humans progresses slowly, and symptoms, viral load, systemic inflammation, and complications vary over the course of the disease. Hence, clinical metadata (e.g., the duration of hospitalization, mechanical ventilation, and the presence of ventilator-associated pneumonia) are necessary to interpret molecular analyses and autopsy studies. Fourth, in the absence of a causal, controlled intervention targeting a specific pathway (e.g., a randomized controlled trial), all human studies are descriptive - at best they can demonstrate associations of any given pathway with severe disease. Finally, even trials of controlled pharmacologic interventions are often challenging to interpret given the widespread adoption of therapies early in the pandemic that were subsequently proven to be effective, lack efficacy, or be harmful $(39,112-118)$, as well as the use of noncomparable control groups (119).

Analysis of peripheral blood. Multiple groups collected cross-sectional and serial peripheral blood samples from patients with severe SARS-CoV-2 pneumonia and subjected immune cells to flow cytometry and single-cell RNA-Seq analysis $(25,27$, 63-67). Data from some of these studies can be explored on the COVID-19 Cell Atlas website (https://www.covid19cellatlas. org/) (120). SARS-CoV-2 infection is accompanied by an increase in neutrophils and lymphopenia. Analysis using flow cytometry panels that distinguish $\mathrm{T}$ cell subsets reveals a loss of all peripheral blood $\mathrm{T}$ cell populations early in the disease, with a particular 
loss of mucosal-associated invariant T (MAIT) cells $(68,69,121)$. Importantly, none of these studies included similarly ill control populations or distinguished patients with ICU complications, including ventilator-associated pneumonia and other nosocomial infections. Furthermore, most of these studies did not normalize sample collection to the date of symptom onset, hospitalization, or initiation of mechanical ventilation.

Analysis of the upper and conductive airways. The nasal epithelium is a primary site for SARS-CoV-2 infection, and secretory cells in the nasal epithelium have the highest expression of ACE2 in the respiratory tract. Some suggest that differences in the epithelial or immune response to SARS-CoV-2 infection in the nasal epithelium determine whether viral replication is controlled or progresses to pneumonia. In particular, differential IFN responses to infection in the nasal epithelium have been suggested to explain the lack of severe disease in children $(122,123)$. However, comparison of the nasal transcriptome in children infected with SARS-CoV-2 and those infected with other respiratory viruses failed to reveal differences in the IFN response $(124,125)$. Furthermore, single-cell transcriptomic profiling of epithelial and immune cells collected from nasal and bronchial brushings confirmed the presence of SARS-CoV-2 in all ACE2-expressing epithelial cells and showed upregulation of IFN-response genes in infected cells (126). Systematic prospective comparison studies of the nasopharyngeal response to infection in patients with mild COVID-19 and patients with upper respiratory disease secondary to other respiratory viruses may offer insights into the pathobiology of severe disease.

Analysis of bronchoalveolar lavage fluid. Bronchoalveolar lavage (BAL) in mechanically ventilated patients is performed by insertion of a fiberoptic bronchoscope through the endotracheal tube and wedging of the tip under direct visualization in a thirdor fourth-generation airway (127). Saline is then instilled into the lung, filling the airspaces distal to the wedged bronchoscope. The fluid is then aspirated with return volumes approximately $20 \%$ of the instilled volume. BAL is safe in critically ill patients, in whom its use to guide antimicrobial therapy has been associated with improved outcomes (127-129). BAL fluid contains inflammatory cells, pathogens, proteins, lipids, and metabolites that are free in the alveolar space and a small number of airway and alveolar epithelial cells that are dislodged during the procedure.

Early in the pandemic, Liao and colleagues provided the first single-cell RNA-Seq analysis of BAL fluid cells from three patients with mild and six patients with severe cases of SARS-CoV-2 pneumonia (130). They found that alveolar fluid from patients with severe SARS-CoV-2 pneumonia lacked tissue-resident alveolar macrophages. Instead, inflammatory monocyte-derived alveolar macrophages (MoAMs) were the most abundant cell type in the BAL fluid. MoAMs from patients with severe SARS-CoV-2 pneumonia contained SARS-CoV-2 transcripts, but they were not detected in alveolar macrophages from patients with mild disease (130). These results were subsequently confirmed by other groups $(126,131,132)$. Since BAL fluid was obtained 11 to 25 days after the onset of symptoms in the severe group, the failure to detect tissue-resident alveolar macrophages (TRAMs) could have resulted from the ongoing recruitment of MoAMs and the death of TRAMs over the course of the disease. These findings have been observed in mouse models of viral and bacterial pneumonia and patients with pneumonia secondary to other pathogens (133-136).

In anticipation of the pandemic, we modified our bronchoscopy protocols to ensure operator safety. Our clinical teams performed bronchoscopies in patients with SARS-CoV-2 pneumonia, as clinically indicated, and used analysis of BAL fluid with quantitative bacterial cultures, multiplex PCR, and fungal antigens to guide antimicrobial therapy $(28,70)$. We compared BAL fluid samples from patients with SARS-CoV-2 pneumonia with serial BAL fluid samples we collected from 211 patients with severe pneumonia secondary to other pathogens requiring mechanical ventilation before the pandemic. The BAL fluid was subjected to flow cytometry analysis, transcriptomic profiling of flow cytometry-sorted alveolar macrophages, and, in a subset of patients, single-cell RNA-Seq (44). We focused on alveolar macrophages, as they sense and respond to inhaled pathogens and particulates and have been causally linked to outcomes after viral pneumonia in animal models (137-140). In particular, we obtained samples within 48 hours of intubation in a substantial number of patients, and microbiologic analysis allowed us to confirm or exclude the presence of coinfecting bacterial pathogens.

Our analysis provided several critical insights (44). First, using flow cytometry, we found that the alveolar space in patients with SARS-CoV-2 pneumonia is enriched for T cells and monocytes and reduced in neutrophils, which contrasts with samples from patients with pneumonia secondary to other pathogens, including influenza. Independently, Roussel et al. observed differential increases in activated classical monocytes and $\mathrm{T}$ cells in peripheral blood samples from patients with SARS-CoV-2 pneumonia and ARDS compared with patients with ARDS secondary to other etiologies (141). Second, we found that the transcriptional signature in alveolar macrophages from patients with severe SARS-CoV-2 pneumonia exhibits a distinct upregulation of IFN-response genes and increased expression of chemokines involved in T cell recruitment, since confirmed by another group (142). Third, in single-cell RNASeq data (which can be explored at https://www.nupulmonary. org), we identified SARS-CoV-2 transcripts in both tissue-resident and MoAMs, including the negative-strand template used for viral replication. Finally, we found that alveolar macrophages harboring SARS-CoV-2 transcripts were transcriptionally distinct from macrophages without viral transcripts. Infected macrophages displayed enhanced expression of IFN-response signatures and increased transcription of $\mathrm{T}$ cell chemokines and inflammatory molecules, including IL1B. Notably, we did not detect increased levels of IL6 in any BAL fluid cell population.

\section{An integrated model of SARS-CoV-2 infection that explains clinical features}

An integrated model developed from the clinical, autopsy, and molecular observations described above offers an explanation for the long temporal course and spatial heterogeneity unique to SARS-CoV-2 pneumonia (Figure 2). After gaining access to the distal lung, SARS-CoV-2 productively infects the small number of ACE2-expressing alveolar epithelial cells, releasing SARS-CoV-2 virions into the alveolar space. These viral particles are ingested by or infect alveolar macrophages. Alveolar macrophages harboring the virus respond by increasing the transcription of $\mathrm{T}$ cell chemo- 


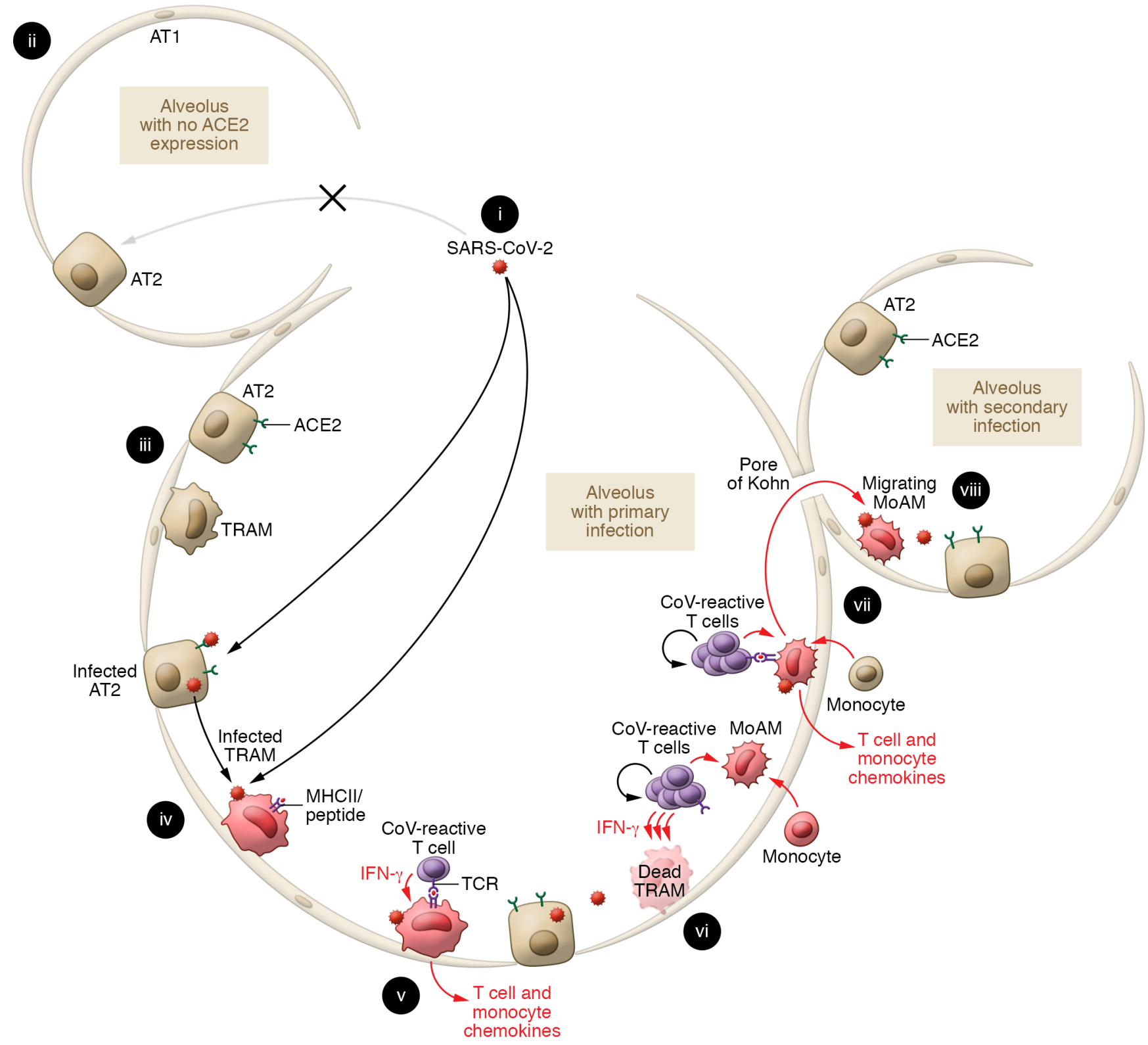

Figure 2. A model for SARS-CoV-2 infection explains the prolonged clinical course and spatial heterogeneity. (i) SARS-CoV-2 spares alveolar epithelial cells that do not express ACE2 (ii) and infects ACE2-expressing alveolar epithelial cells (iii), allowing uptake by alveolar macrophages (iv). Alveolar macrophages harboring viruses release chemokines that recruit T cells and monocytes to the alveolus (v). T cells induce macrophage apoptosis, further driving the recruitment of MoAMs (vi). These recruited macrophages take up SARS-CoV-2, resulting in self-sustaining inflammatory circuits. Macrophages harboring virus can migrate to adjacent alveoli (vii), where they can initiate inflammatory circuits with T cells and infect ACE2-expressing epithelial cells (viii), whereupon the process repeats itself from steps v-viii. AT1, type 1 alveolar epithelial cell.

kines and perhaps activating the NLRP3 inflammasome. These events may induce the activation of coronavirus cross-reactive memory T cells (143-146). Alveolar macrophage death might be caused by the viral infection or by the release of IFN- $\gamma$ and TRAIL (TNF-related apoptosis-inducing ligand) from activated $\mathrm{T}$ cells (44), which induces alveolar macrophage apoptosis in murine models of influenza A infection (147). Depletion of the alveolar macrophage niche combined with epithelial injury and production of chemoattractants, such as CCL2, by activated T cells induces the recruitment of monocytes, which rapidly differentiate into MoAMs $(136,148)$. These MoAMs also take up or are infected by
SARS-CoV-2 and, once activated by IFN- $\gamma$, recruit additional T cells. These self-sustaining inflammatory signaling loops between alveolar macrophages harboring virus, and activated $\mathrm{T}$ cells, persist until the virus is cleared.

How SARS-CoV-2 spreads to adjacent lung regions is less clear (Figure 3). The fundamental anatomical structure of the lung responsible for gas exchange is the secondary pulmonary lobule (also called the pulmonary lobule), which is bordered by interstitial connective tissue (interlobular septa) and fed by a single bronchiole and pulmonary artery. Each secondary pulmonary lobule contains up to 30 acini, each of which contains thousands of 
A Uncomplicated severe influenza pneumonia

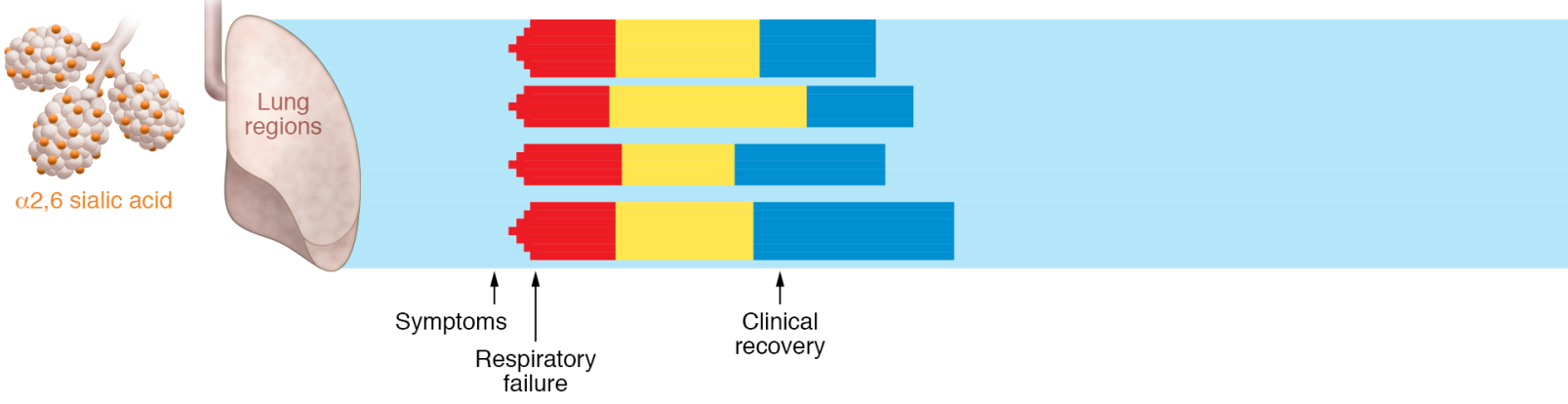

B Uncomplicated severe SARS-CoV-2 pneumonia

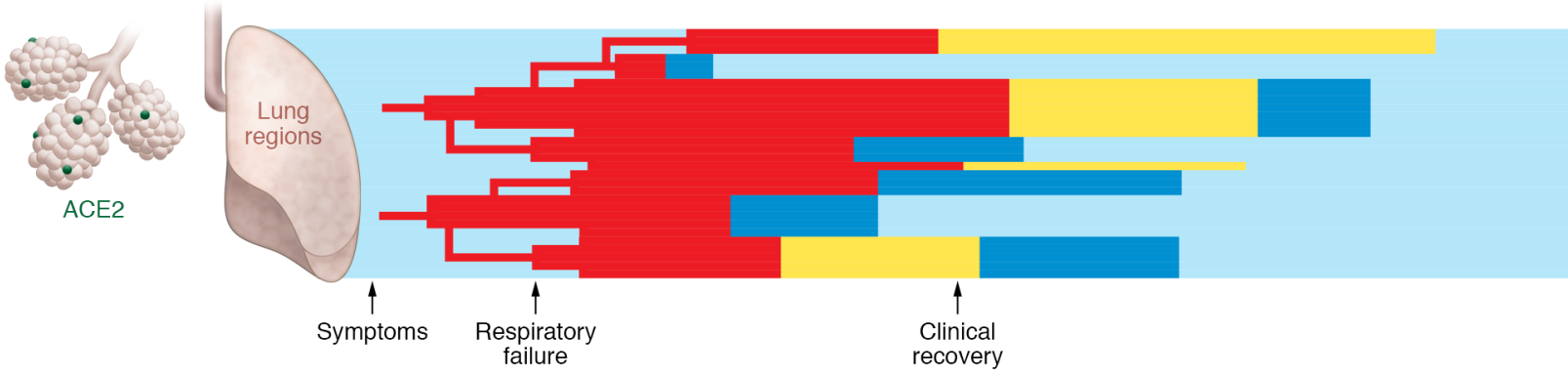

C Fatal severe SARS-CoV-2 pneumonia
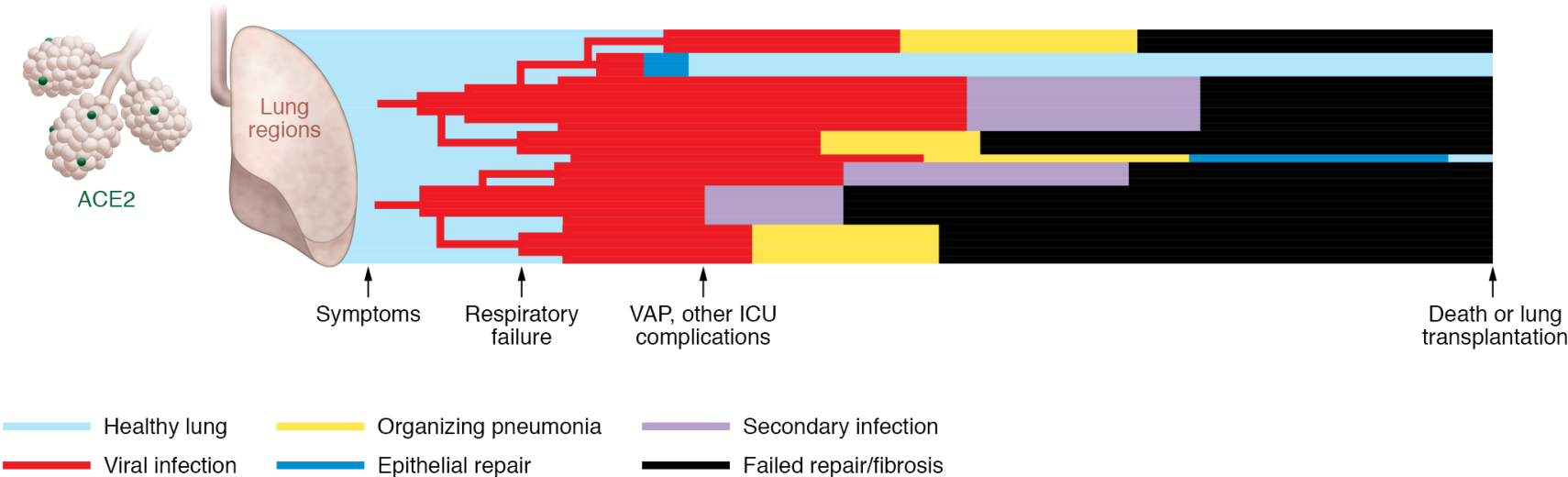

Figure 3. Sparse airway and alveolar epithelial expression of ACE2 slows viral spread across the lung and prolongs the clinical course. (A) In influenza virus infection, abundant airway and alveolar epithelial cell expression of a2,6-linked sialic acid residues, the receptors for influenza viruses, enables a rapid spread across the lung and a short clinical course. Injury, viral clearance, and alveolar fibrosis or repair occur synchronously over the course of the illness. (B and C) In SARS-CoV-2 infection, sparse ACE2 expression results in spatially restricted areas of normal lung, ongoing injury, viral clearance, and alveolar fibrosis or repair in different lung regions.

alveoli that are ventilated by a single terminal bronchiole, which is the last airway division that does not itself bear alveoli. The sparsity of ACE2 expression in the distal lung poses a challenge for intra- and interlobular viral spread. Early in the pandemic, studies in cultured lung epithelial cells suggested that infection with SARS-CoV-2 results in IFN-induced expression of ACE2 in adjacent cells (93). However, evidence supporting this mechanism has not been found in lung tissues at autopsy or in precision-cut lung slices infected with SARS-CoV-2 $(60,89,93)$. Alternatively, alveolar macrophages, once described as sessile, have recently been reported to travel across distances of several alveoli, or directly between them via pores of Kohn, particularly during viral infection $(149,150)$. Hence, infected alveolar macrophages might serve to spread the virus to adjacent lung regions. Upon alveolar macrophage death, the released virus could infect ACE2-expressing alveolar epithelial cells. MoAMs, perhaps recruited to pulmonary lobules rather than individual alveoli, might amplify this process (151). Further supporting this model, active viral shedding has been observed up to 18 days after infection in nasal samples from critically ill patients with SARS-CoV-2 pneumonia, which is longer than that reported for patients with less severe disease $(152,153)$.

This model is consistent with the observed responses to therapy in patients with SARS-CoV-2 pneumonia. Antiviral agents, like remdesivir, may slow the progression of SARS-CoV-2 across the lung, shortening the duration of illness $(154,155)$. Corticosteroids, which broadly suppress inflammatory signals, could 
modulate inflammation in $\mathrm{T}$ cells and macrophages to limit immunopathology $(114,118)$. JAK inhibitors, like baricitinib, are predicted to reduce IFN signaling in alveolar macrophages, attenuating signaling loops between activated $\mathrm{T}$ cells and macrophages (156). In our model of slowly progressive disease, we suggest that all of these therapies will be effective only in the subset of patients with alveolar involvement, clinically marked by hypoxemia requiring hospitalization. In addition, all of the therapies will be more effective when administered early in the course of severe disease when the ratio of at-risk to involved lung regions is highest, and will have no benefit or be harmful in patients with mild or moderate disease.

\section{Unanswered questions}

How does SARS-CoV-2 get into alveolar macrophages? In almost all autopsy studies of patients who died early from SARS-CoV-2 pneumonia, viral particles or viral RNA are detected in alveolar macrophages. SARS-CoV-2-infected alveolar macrophages were found during ex vivo infection of precision-cut lung slices (157). SARSCoV-2 transcripts were also detected in alveolar macrophages isolated from BAL fluid obtained from patients with SARS-CoV-2 pneumonia $(126,130,158)$. Data from studies using sm-FISH, single-cell RNA-Seq and immunohistochemistry with validated antibodies definitively show that ACE2 is not expressed on alveolar macrophages $(60,159)$. Viral particles might enter the macrophage via efferocytosis of dying epithelial cells. This hypothesis is unlikely, as genes specific to epithelial cells (e.g., genes encoding keratins or EPCAM) are not found in alveolar macrophages harboring SARS-CoV-2 transcripts collected from BAL fluid $(44,130)$. Alternatively, the virus might enter macrophages through antibody-dependent enhancement. In this mechanism, antibodies bound to the virus facilitate viral entry via $\mathrm{Fc}$ receptors on the alveolar macrophage, as shown during in vitro infection of macrophages with SARS-CoV and MERS-CoV $(160,161)$. This mechanism has received considerable attention, as the presence of cross-reactive antibodies, perhaps generated in response to historical coronavirus infections, might explain more severe disease in some individuals (162). In support of this hypothesis, about $20 \%$ of the population had circulating antibodies before the pandemic that cross-react with SARS-CoV-2 (146). Levels of these antibodies were increased upon SARS-CoV-2 infection but were not protective. Li et al. isolated neutralizing and non-neutralizing antibodies from patients with a history of SARS-CoV-2 or SARS-CoV infection and showed that some of them were capable of inducing antibody-mediated enhancement in cultured cells lacking ACE2 receptors (163). However, when antibodies demonstrating in vitro enhancement were infused into monkeys, only one of 30 animals developed severe disease. These data show that in vitro evidence of antibody-mediated enhancement does not predict in vivo antibody-mediated enhancement. However, the low rate of severe disease observed in the monkeys leaves open the possibility of antibody-mediated enhancement as an explanation for the relatively infrequent development of severe disease in humans.

Which population of alveolar macrophages does SARS-CoV-2 infect? The population of alveolar macrophages in an acutely inflamed lung is heterogeneous and typically contains at least two distinct subsets of alveolar macrophages (148). TRAMs are abundant in the healthy, uninjured lung, where they perform removal of surfactant and apoptotic cells and immune surveillance. MoAMs are rarely found in the normal lung but are recruited to regions of injury, where they often substantially outnumber TRAMs. MoAMs exhibit an inflammatory profile and drive collateral damage to lung tissue (148). Single-cell transcriptomic studies have demonstrated that SARS-CoV-2 infects both tissue-resident and MoAMs (44, 126, 130, 131), but whether these macrophage subsets have a differential capacity for maintaining or spreading SARS-CoV-2 is not clear.

How do alveolar $T$ cells become activated, and what is their antigen specificity? Alveolar macrophages are poor antigen-presenting cells and do not migrate to lymph nodes to participate in converting naive T cells into effector T cells $(164,165)$. Nevertheless, alveolar macrophages can provide low levels of antigen presentation that might be sufficient to drive activation of preexisting memory $\mathrm{T}$ cells that cross-react with SARS-CoV-2 (165). The ability of infected macrophages to activate $\mathrm{T}$ cells and MAIT cells was demonstrated in vitro using peripheral blood monocyte-derived macrophages (166). Cross-reactive memory T cells for SARS-CoV (167) and SARS-CoV-2 have been observed in uninfected patients, but whether they are protective or increase the risk for disease is not clear $(143,144,168-170)$. In many of these reports, crossreactive $\mathrm{T}$ cells were suggested to arise from prior exposure to other coronaviruses. Bacher et al. tested this hypothesis directly and found that cross-reactive T cells from patients with COVID-19 lacked cross-reactivity to common cold coronaviruses (170). They further found that SARS-CoV-2-specific T cells with low functional avidity were more common in patients with severe disease.

What are the mechanistic underpinnings of SARS-CoV-2 epidemiology? The mechanistic basis for the increased risk of severe disease or death in patients with advanced age, obesity, diabetes, or hypertension, and for the lack of severe disease in younger patients, is not clear. Genetic studies have identified polymorphisms in several genes associated with disease severity, including genes encoding type I IFN signaling $(171,172)$, monocyte recruitment (172), ABO blood group $(173,174)$, and fibrosis (174). Others suggest that increased expression of ACE2 in the respiratory tract of people with known risk factors drives more severe disease. An analysis of single-cell RNA-Seq data from normal human lungs suggested that ACE2 expression is modestly increased in men compared with women and in older individuals, and suggested very low expression in pediatric compared with adult patients (159). However, similar levels of ACE2 expression were observed in bulk RNA-Seq of samples from the nasal epithelium of pediatric and adult patients (125).

What cells are the source of systemic inflammatory cytokines? High levels of IL-6 and its transcriptional target C-reactive protein predict mortality in patients with severe SARS-CoV-2 pneumonia, and therapies targeting the IL- 6 receptor in patients with COVID-19 have been extensively used to treat these patients despite mixed results in clinical trials (112, 113, 115-117, 175). Increased IL6 transcripts were not detected in the peripheral blood of circulating immune cells from patients with severe, compared with mild, COVID-19 or healthy controls (25). Similarly, IL6 transcripts were not increased in inflammatory cells obtained from BAL fluid of patients with SARS-CoV-2 pneumonia $(44,130)$. 
In single-cell RNA-Seq data from the lungs of patients with pulmonary fibrosis, endothelial cells and fibroblasts express the highest levels of IL6 $(176,177)$. Further studies will be required to determine the source of IL- 6 and other circulating inflammatory cytokines in patients with SARS-CoV-2 pneumonia.

\section{Summary and conclusions}

Despite its numerous extrapulmonary complications, severe COVID-19 is primarily a respiratory disease best understood as a severe viral pneumonia. Distinguishing clinical features of pneumonia caused by SARS-CoV-2 compared with other pathogens include the slow temporal pace of disease and recovery, the spatial heterogeneity of SARS-CoV-2 pneumonia, and the relative absence of severe disease in children. Data from autopsy studies and examination of distal lung immune cell populations have provided insights into the molecular pathogenesis of severe SARSCoV-2 pneumonia and explain many of the bedside observations. Tractable animal models and in vitro systems that recapitulate the clinical features of the severe lung disease seen in humans are needed to causally test hypotheses generated from human observational data. Studies of interventions in humans need to be sup- ported by biomarker studies that include nasopharyngeal, airway, and alveolar samples to understand viral involvement and host response across the respiratory system.

\section{Acknowledgments}

GRSB was supported by NIH grants U19AI135964, P01AG049665, R01HL147575, P01HL071643, and R01HL154686 and Veterans Affairs grant I01CX001777. AVM was supported by NIH grants U19AI135964, P01AG049665, R56HL135124, and R01HL153312 and a Northwestern University Clinical and Translational Sciences Institute COVID-19 Rapid Response Grant. KMR was supported by NIH grants P01AG049665 and P01HL071643. BDS was supported by NIH awards U19AI135964, R01HL149883, R01HL153122, and P01AG049665. RGW was supported by NIH grant U19AI135964 and a GlaxoSmithKline Distinguished Scholar in Respiratory Health grant from the CHEST Foundation.

Address correspondence to: G.R. Scott Budinger, Pulmonary and Critical Care Medicine, Northwestern University, 303 E. Superior Street, Simpson Querrey, 5th Floor, Chicago, Illinois 60611, USA. Phone: 312.908.8163; Email: s-buding@northwestern.edu.
1. Anderson EJ, et al. Safety and immunogenicity of SARS-CoV-2 mRNA-1273 vaccine in older adults. N Engl JMed. 2020;383(25):2427-2438.

2. Polack FP, et al. Safety and efficacy of the BNT162b2 mRNA Covid-19 vaccine. $N$ Engl J Med. 2020;383(27):2603-2615.

3. Voysey M, et al. Safety and efficacy of the ChAdOx1 nCoV-19 vaccine (AZD1222) against SARS-CoV-2: an interim analysis of four randomised controlled trials in Brazil, South Africa, and the UK. Lancet. 2021;397(10269):99-111.

4. Sadoff J, et al. Interim results of a phase 1-2a trial of Ad26.COV2.S Covid-19 vaccine. $N$ Engl J Med. 2021;384(19):1824-1835.

5. Logunov DY, et al. Safety and efficacy of an rAd26 and rAd5 vector-based heterologous prime-boost COVID-19 vaccine: an interim analysis of a randomised controlled phase 3 trial in Russia. Lancet. 2021;397(10275):671-681.

6. Poeschla E. Neutralizing SARS-CoV-2. Elife. 2020;9:e64496.

7. Weisblum Y, et al. Escape from neutralizing antibodies by SARS-CoV-2 spike protein variants. Elife. 2020;9:e61312.

8. Hacisuleyman E, et al. Vaccine breakthrough infections with SARS-CoV-2 variants [published online April 21, 2021]. N Engl J Med. https://doi. org/10.1056/nejmoa2105000.

9. Davies NG, et al. Estimated transmissibility and impact of SARS-CoV-2 lineage B.1.1.7 in England. Science. 2021;372(6538):eabg3055.

10. World Health Organization. WHO R\&D Blueprint. Novel Coronavirus: COVID-19 Therapeutic Trial Synopsis. https://www.who.int/ blueprint/priority-diseases/key-action/COVID19_Treatment_Trial_Design_Master_Protocol_ synopsis_Final_18022020.pdf. Updated February 18, 2020. Accessed April 26, 2021.

11. National Institutes of Health. Clinical Spectrum of SARS-CoV-2 Infection. https://www. covid19treatmentguidelines.nih.gov/overview/ clinical-spectrum/. Updated April 21, 2021.

Accessed February 22, 2021.

12. Kochanek KD, et al. Deaths: final data for 2017. Natl Vital Stat Rep. 2019;68(9):1-77.

13. Calfee CS, et al. Subphenotypes in acute respiratory distress syndrome: latent class analysis of data from two randomised controlled trials. Lancet Respir Med. 2014;2(8):611-620.

14. Jain S, et al. Community-acquired pneumonia requiring hospitalization among U.S. Adults. N Engl J Med. 2015;373(5):415-427.

15. Huang C, et al. Clinical features of patients infected with 2019 novel coronavirus in Wuhan, China. Lancet. 2020;395(10223):497-506.

16. Chen N, et al. Epidemiological and clinical characteristics of 99 cases of 2019 novel coronavirus pneumonia in Wuhan, China: a descriptive study. Lancet. 2020;395(10223):507-513.

17. Grasselli G, et al. Baseline characteristics and outcomes of 1591 patients infected with SARSCoV-2 admitted to ICUs of the Lombardy Region, Italy. JAMA. 2020;323(16):1574-1581.

18. Horby P, et al. Effect of dexamethasone in hospitalized patients with COVID-19: preliminary report. N Eng JMed. 2021;384:693-704.

19. Argenziano MG, et al. Characterization and clinical course of 1000 patients with coronavirus disease 2019 in New York: retrospective case series. BMJ. 2020;369:m1996.

20. Chand S, et al. COVID-19-associated critical illness-report of the first 300 patients admitted to intensive care units at a New York City Medical Center. J Intensive Care Med. 2020;35(10):963-970.

21. Zhu N, et al. A novel coronavirus from patients with pneumonia in China, 2019. N Engl J Med. 2020;382(8):727-733.

22. Chan JFW, et al. Genomic characterization of the 2019 novel human-pathogenic coronavirus isolated from a patient with atypical pneumonia after visiting Wuhan. Emerg Microbes Infect.
2020;9(1):221-236

23. Coronaviridae Study Group of the International Committee on Taxonomy of Viruses. The species Severe acute respiratory syndrome-related coronavirus: classifying 2019-nCoV and naming it SARS-CoV-2. Nat Microbiol. 2020;5(4):536-544.

24. Hadjadj J, et al. Impaired type I interferon activity and inflammatory responses in severe COVID-19 patients. Science. 2020;369(6504):718-724.

25 . Wilk AJ, et al. A single-cell atlas of the peripheral immune response in patients with severe COVID-19. Nat Med. 2020;26(7):1070-1076.

26. Blanco-Melo D, et al. Imbalanced host response to SARS-CoV-2 drives development of COVID19. Cell. 2020;181(5):1036-1045.

27. Mathew D, et al. Deep immune profiling of COVID-19 patients reveals distinct immunotypes with therapeutic implications Science. 2020;369(6508):eabc8511.

28. Gao CA, et al. Bronchoscopy on intubated COVID-19 patients is associated with low infectious risk to operators [published online January 15, 2021]. Ann Am Thorac Soc. https://doi. org/10.1513/annalsats.202009-1225rl.

29. Gattinoni L, et al. COVID-19 does not lead to a "typical" acute respiratory distress syndrome. Am JRespir Crit Care Med. 2020;201(10):1299-1300.

30. Marini JJ, Gattinoni L. Management of COVID-19 respiratory distress. JAMA. 2020;323(22):2329-2330.

31. Sakurai A, et al. Natural history of asymptomatic SARS-CoV-2 infection. $N$ Engl J Med. 2020;383(9):885-886.

32. Arons MM, et al. Presymptomatic SARS-CoV-2 infections and transmission in a skilled nursing facility. N Engl J Med. 2020;382(22):2081-2090.

33. Baggett TP, et al. Prevalence of SARS-CoV-2 infection in residents of a large homeless shelter in Boston. JAMA. 2020;323(21):2191-2192.

34. Campbell KH, et al. Prevalence of SARS-CoV-2 
among patients admitted for childbirth in Southern Connecticut. JAMA. 2020;323(24):2520-2522.

35 . Louie JK, et al. Lessons from mass-testing for COVID-19 in long term care facilities for the elderly in San Francisco. Clin Infect Dis. 2021;72(11):2018-2020.

36. Kasper MR, et al. An outbreak of Covid19 on an aircraft carrier. $N$ Engl J Med. 2020;383(25):2417-2426.

37. Letizia AG, et al. SARS-CoV-2 transmission among marine recruits during quarantine. N Engl J Med. 2020;383(25):2407-2416.

38. Wu Z, McGoogan JM. Characteristics of and important lessons from the Coronavirus Disease 2019 (COVID-19) outbreak in China: summary of a report of 72314 cases from the Chinese Center for Disease Control and Prevention. JAMA. 2020;323(13):1239-1242.

39. Tomazini BM, et al. Effect of dexamethasone on days alive and ventilator-free in patients with moderate or severe acute respiratory distress syndrome and COVID-19: the CoDEX Randomized Clinical Trial. JAMA. 2020;324(13):1307-1316.

40. ARDS Definition Task Force, et al. Acute respiratory distress syndrome: the Berlin definition. JAMA. 2012;307(23):2526-2533.

41. Ferrando C, et al. Clinical features, ventilatory management, and outcome of ARDS caused by COVID-19 are similar to other causes of ARDS. Intensive Care Med. 2020;46(12):2200-2211.

42. Gamberini L, et al. Factors influencing liberation from mechanical ventilation in coronavirus disease 2019: multicenter observational study in fifteen Italian ICUs. J Intensive Care Med. 2020;8(1):80.

43. Roedl K, et al. Mechanical ventilation and mortality among 223 critically ill patients with coronavirus disease 2019: a multicentric study in Germany. Aust Crit Care. 2021;34(2):167-175.

44. Grant RA, et al. Circuits between infected macrophages and T cells in SARS-CoV-2 pneumonia. Nature. 2021;590(7847):635-641.

45. Guan WJ, et al. Clinical characteristics of Coronavirus Disease 2019 in China. N EnglJ Med. 2020;382(18):1708-1720.

46. Churpek MM, et al. Hospital-level variation in death for critically ill patients with COVID-19 [published online April 23, 2021]. Am J Respir Crit Care Med. https://doi.org/10.1164/rccm.202012$4547 \mathrm{OC}$.

47. Herold T, et al. Elevated levels of IL- 6 and CRP predict the need for mechanical ventilation in COVID-19. J Allergy Clin Immunol. 2020;146(1):128-136.

48. Del Valle DM, et al. An inflammatory cytokine signature predicts COVID-19 severity and survival. Nat Med. 2020;26(10):1636-1643.

49. Yang X, et al. Clinical course and outcomes of critically ill patients with SARS-CoV-2 pneumonia in Wuhan, China: a single-centered, retrospective, observational study. Lancet Respir Med. 2020;8(5):475-481.

50. Kox M, et al. Cytokine levels in critically ill patients with COVID-19 and other conditions [published online September 3, 2020]. JAMA https://doi.org/10.1001/jama.2020.17052.

51. Leisman DE, et al. Cytokine elevation in severe and critical COVID-19: a rapid systematic review, meta-analysis, and comparison with other inflammatory syndromes. Lancet Respir Med. 2020;8(12):1233-1244.

52. El Solh A, et al. Determinants of short and long term functional recovery after hospitalization for community-acquired pneumonia in the elderly: role of inflammatory markers. BMC Geriatr. 2006;6:12.

53. Puren AJ, et al. Patterns of cytokine expression in community-acquired pneumonia. Chest. 1995;107(5):1342-1349.

54. Almirall J, et al. Contribution of C-reactive protein to the diagnosis and assessment of severity of community-acquired pneumonia. Chest. 2004;125(4):1335-1342.

55. Antunes G, et al. Systemic cytokine levels in community-acquired pneumonia and their association with disease severity. Eur Respir J. 2002;20(4):990-995

56. Filbin MR, et al. Plasma proteomics reveals tissue-specific cell death and mediators of cell-cell interactions in severe COVID-19 patients [preprint]. https://doi. org/10.1101/2020.11.02.365536. Posted on bioRxiv November 3, 2020.

57. van der Zee P, et al. A systematic review of biomarkers multivariately associated with acute respiratory distress syndrome development and mortality. Crit Care. 2020;24(1):243.

58. Bradley BT, et al. Histopathology and ultrastructural findings of fatal COVID-19 infections in Washington State: a case series. Lancet. 2020;396(10247):320-332.

59. Bhatnagar J, et al. Evidence of SARS-CoV-2 replication and tropism in the lungs, airways and vascular endothelium of patients with fatal COVID-19: an autopsy case-series. JInfect Dis. 2021;223(5):752-764.

60. Hönzke K, et al. Human lungs show limited permissiveness for SARS-CoV-2 due to scarce ACE2 levels but strong virus-induced immune activation in alveolar macrophages [published online October 6, 2020]. Cell. https://doi.org/10.2139/ ssrn.3687020.

61. Grignani G, Maiolo A. Cytokines and hemostasis Haematologica. 2000;85(9):967-972.

62. Soberanes S, et al. Metformin targets mitochondrial electron transport to reduce air-pollution-induced thrombosis. Cell Metab. 2019;29(2):503

63. Xu G, et al. The differential immune responses to COVID-19 in peripheral and lung revealed by single-cell RNA sequencing. Cell Discov. 2020;6:73.

64. Zhang JY, et al. Single-cell landscape of immunological responses in patients with COVID-19. Nat Immunol. 2020;21(9):1107-1118.

65. Schulte-Schrepping J, et al. Severe COVID-19 is marked by a dysregulated myeloid cell compartment. Cell. 2020;182(6):1419-1440.

66. Zhu L, et al. Single-cell sequencing of peripheral mononuclear cells reveals distinct immune response landscapes of COVID-19 and influenza patients. Immunity. 2020;53(3):685-696.

67. Zheng Y, et al. A human circulating immune cell landscape in aging and COVID-19. Protein Cell. 2020;11(10):740-770.

68. Marsh JC, et al. Neutrophil kinetics in acute infection. J Clin Invest. 1967;46(12):1943-1953.
69. Bermejo-Martin JF, et al. Lymphopenic community acquired pneumonia (L-CAP), an immunological phenotype associated with higher risk of mortality. EBioMedicine. 2017;24:231-236.

70. Pickens CO, et al. Bacterial superinfection pneumonia in SARS-CoV-2 respiratory failure [preprint]. https://doi.org/10.1101/2021.01.12.2024 8588

71. Altmayer S, et al. Comparison of the computed tomography findings in COVID-19 and other viral pneumonia in immunocompetent adults: a systematic review and meta-analysis. Eur Radiol. 2020;30(12):6485-6496

72. Hu Z, et al. Clinical characteristics of 24 asymptomatic infections with COVID-19 screened among close contacts in Nanjing, China. Sci China Life Sci. 2020;63(5):706-711.

73. Wang Y, et al. Clinical outcomes in 55 patients with severe acute respiratory syndrome Coronavirus 2 who were asymptomatic at hospital admission in Shenzhen, China. J Infect Dis. 2020;221(11):1770-1774.

74. Li Q, et al. Early transmission dynamics in Wuhan, China, of novel Coronavirus-infected pneumonia. NEngl J Med. 2020;382(13):1199-1207.

75. Hong SB, et al. Epidemiological analysis of critically ill adult patients with pandemic influenza A(H1N1) in South Korea. Epidemiol Infect. 2013;141(5):1070-1079.

76. Nin N, et al. Clinical characteristics and outcomes of patients with 2009 influenza A(H1N1) virus infection with respiratory failure requiring mechanical ventilation. JCrit Care. 2011;26(2):186-192.

77. Bharat A, et al. Early outcomes after lung transplantation for severe COVID-19: a series of the first consecutive cases from four countries. Lancet Respir Med. 2021;9(5):487-497.

78. Bhat $\mathrm{N}$, et al. Influenza-associated deaths among children in the United States, 2003-2004. N Engl JMed. 2005;353(24):2559-2567.

79. Jain S, et al. Hospitalized patients with 2009 H1N1 influenza in the United States, April-June 2009. N Engl JMed. 2009;361(20):1935-1944.

80. Zimmermann P, Curtis N. Coronavirus infections in children including COVID-19: an overview of the epidemiology, clinical features, diagnosis, treatment and prevention options in children. Pediatr Infect Dis J. 2020;39(5):355-368.

81. Pijls BG, et al. Demographic risk factors for COVID-19 infection, severity, ICU admission and death: a meta-analysis of 59 studies. BMJ Open. 2021;11(1):e044640.

82. Mudatsir M, et al. Predictors of COVID-19 severity: a systematic review and meta-analysis. F1000Res. 2020;9:1107.

83. Popkin BM, et al. Individuals with obesity and COVID-19: a global perspective on the epidemiology and biological relationships. Obes Rev. 2020;21(11):e13128.

84. Allard R, et al. Diabetes and the severity of pandemic influenza A (H1N1) infection. Diabetes Care. 2010;33(7):1491-1493.

85. Schoen K, et al. Spectrum of clinical and radiographic findings in patients with diagnosis of H1N1 and correlation with clinical severity. BMC Infect Dis. 2019;19(1):964.

86. Fezeu L, et al. Obesity is associated with higher 
risk of intensive care unit admission and death in influenza A (H1N1) patients: a systematic review and meta-analysis. Obes Rev. 2011;12(8):653-659.

87. V'kovski P, et al. Coronavirus biology and replication: implications for SARS-CoV-2. Nat Rev Microbiol. 2021;19(3):155-170.

88. Chu $\mathrm{H}$, et al. Host and viral determinants for efficient SARS-CoV-2 infection of the human lung. Nat Commun. 2021;12(1):134.

89. Hou YJ, et al. SARS-CoV-2 reverse genetics reveals a variable infection gradient in the respiratory tract. Cell. 2021;182(2):429-446.

90. Walls AC, et al. Structure, function, and antigenicity of the SARS-CoV-2 spike glycoprotein. Cell. 2020;181(2):281-292.

91. Konno Y, et al. SARS-CoV-2 ORF3b is a potent interferon antagonist whose activity is increased by a naturally occurring elongation variant. Cell Rep. 2020;32(12):108185.

92. Martines RB, et al. Pathology and pathogenesis of SARS-CoV-2 associated with fatal Coronavirus Disease, United States. Emerg Infect Dis. 2020;26(9):2005-2015.

93. Ziegler CGK, et al. SARS-CoV-2 receptor ACE2 is an interferon-stimulated gene in human airway epithelial cells and is detected in specific cell subsets across tissues. Cell. 2020;181(5):1016-1035.

94. Sungnak W, et al. SARS-CoV-2 entry factors are highly expressed in nasal epithelial cells together with innate immune genes. Nat Med. 2020;26(5):681-687.

95. Samet JM, et al. Airborne transmission of SARS-CoV-2: what we know [published online January 18, 2021]. Clin Infect Dis. https://doi. org/10.1093/cid/ciab039.

96. Tumpey TM, et al. A two-amino acid change in the hemagglutinin of the 1918 influenza virus abolishes transmission. Science. 2007;315(5812):655-659.

97. Yang ZY, et al. Immunization by avian H5 influenza hemagglutinin mutants with altered receptor binding specificity. Science. 2007;317(5839):825828.

98. Nienhold R, et al. Two distinct immunopathological profiles in autopsy lungs of COVID-19. Nat Commun. 2020;11(1):5086

99. Delorey TM, et al. COVID-19 tissue atlases reveal SARS-CoV-2 pathology and cellular targets [published online April 29, 2021]. Nature. https://doi. org/10.1038/s41586-021-03570-8.

100. Bharat A, et al. Lung transplantation for patients with severe COVID-19. Sci Transl Med. 2020;12(574):eabe4282.

101. Konopka KE, et al. Diffuse alveolar damage (DAD) resulting from coronavirus disease 2019 infection is morphologically indistinguishable from other causes of DAD. Histopathology. 2020;77(4):570-578

102. Hariri LP, et al. Lung histopathology in Coronavirus disease 2019 as compared with severe acute respiratory sydrome and $\mathrm{H} 1 \mathrm{~N} 1$ influenza: a systematic review. Chest. 2021;159(1):73-84.

103. Desai N, et al. Temporal and spatial heterogeneity of host response to SARS-CoV-2 pulmonary infection. Nat Commun. 2020;11(1):6319.

104. Kulasinghe A, et al. Spatial profiling of lung SARS$\mathrm{CoV}-2$ and influenza virus infection dissects virus-specific host responses and gene signatures [preprint]. https://doi.org/10.1101/2020.11.04.2 0225557. Posted on bioRxiv November 6, 2020.

105. Andersson MI, et al. SARS-CoV-2 RNA detected in blood products from patients with COVID-19 is not associated with infectious virus. Wellcome Open Res. 2020;5:181.

106.Edlow AG, et al. Assessment of maternal and neonatal SARS-CoV-2 viral load, transplacental antibody transfer, and placental pathology in pregnancies during the COVID-19 pandemic. JAMA Netw Open. 2020;3(12):e2030455.

107. Chen $\mathrm{H}$, et al. Clinical characteristics and intrauterine vertical transmission potential of COVID-19 infection in nine pregnant women: a retrospective review of medical records. Lancet. 2020;395(10226):809-815.

108.Zeng L, et al. Neonatal early-onset infection with SARS-CoV-2 in 33 neonates born to mothers with COVID-19 in Wuhan, China. JAMA Pediatr. 2020;174(7):722-725

109. Farouk SS, et al. COVID-19 and the kidney: what we think we know so far and what we don't. J Nephrol. 2020;33(6):1213-1218.

110. Miller SE, Brealey JK. Visualization of putative coronavirus in kidney. Kidney Int . 2020;98(1):231-232.

111. Lau WL, et al. The COVID-kidney controversy: can SARS-CoV-2 cause direct renal infection? Nephron. 2021;145(3):275-279.

112. Veiga VC, et al. Effect of tocilizumab on clinica outcomes at 15 days in patients with severe or critical coronavirus disease 2019: randomised controlled trial. BMJ. 2021;372:n84.

113. Sanofi. Sanofi Provides Update on Kevzara (Sarilumab) Phase 3 Trial in Severe and Critically Ill COVID-19 Patients Outside the U.S. https:// www.sanofi.com/en/media-room/press-releases/2020/2020-09-01-07-00-00. Updated September 1, 2020. Accessed February 4, 2021.

114. RECOVERY Collaborative Group, et al. Effect of hydroxychloroquine in hospitalized patients with Covid-19. N Engl J Med. 2020;383(21):2030-2040.

115. Stone JH, et al. Efficacy of tocilizumab in patients hospitalized with Covid-19. N Engl J Med. 2020;383(24):2333-2344.

116. Lescure FX, et al. Sarilumab in patients admitted to hospital with severe or critical COVID-19: a randomised, double-blind, placebo-controlled, phase 3 trial. Lancet Respir Med. 2021;9(5):522-532.

117. REMAP-CAP Investigators, et al. Interleukin-6 receptor antagonists in critically ill patients with Covid-19. N Engl J Med. 2021;384(16):1491-1502.

118. Angus DC, et al. Effect of hydrocortisone on mortality and organ support in patients with severe COVID-19: the REMAP-CAP COVID-19 corticosteroid domain randomized clinical trial. JAMA. 2020;324(13):1317-1329.

119. Dodd LE, et al. Platform trials - beware the noncomparable control group. N Engl JMed. 2021;384(16):1572-1573.

120. Chan Zuckerberg Initiative Single-Cell COVID19 Consortia, et al. Single cell profiling of COVID-19 patients: an international data resource from multiple tissues [preprint]. https:// doi.org/10.1101/2020.11.20.20227355. Posted on bioRxiv November 23, 2020.

121. Parrot T, et al. MAIT cell activation and dynamics associated with COVID-19 disease severity. Sci
Immunol. 2020;5(51):eabe1670.

122. Vabret N, et al. Immunology of COVID-19: current state of the science. Immunity. 2020;52(6):910-941.

123. Steinman JB, et al. Reduced development of COVID-19 in children reveals molecular checkpoints gating pathogenesis illuminating potential therapeutics. Proc Natl Acad Sci US A. 2020;117(40):24620-24626.

124. Mick E, et al. Upper airway gene expression reveals suppressed immune responses to SARS-CoV-2 compared with other respiratory viruses. Nat Commun. 2020;11(1):5854.

125. Koch CM, et al. Immune response to SARSCoV-2 in the nasal mucosa in children and adults [preprint]. Posted on bioRxiv January 28, 2021. https://doi.org/10.1101/2021.01.26.21250269.

126. Chua RL, et al. COVID-19 severity correlates with airway epithelium-immune cell interactions identified by single-cell analysis. Nat Biotechnol. 2020;38(8):970-979.

127. Walter JM, et al. Multidimensional assessment of alveolar T cells in critically ill patients. JCI Insight. 2018;3(17):e123287.

128. Torres A, et al. International ERS/ESICM/ESCMID/ALAT guidelines for the management of hospital-acquired pneumonia and ventilatorassociated pneumonia: Guidelines for the management of hospital-acquired pneumonia (HAP)/ ventilator-associated pneumonia (VAP) of the European Respiratory Society (ERS), European Society of Intensive Care Medicine (ESICM), European Society of Clinical Microbiology and Infectious Diseases (ESCMID) and Asociación Latinoamericana del Tórax (ALAT). Eur Respir J. 2017;50(3):1700582.

129. Pickens C, et al. Use of a methicillin-resistant Staphylococcus aureus (MRSA) automated polymerase chain reaction (A-PCR) assay significantly decreases vancomycin use in the medical intensive care unit. Paper presented at: American Thoracic Society 2019 International Conference; May 17-22, 2019; Dallas, Texas, USA. doi:10.1164/ajrccm-conference.2019.199.1 meetingabstracts.a4124. Accessed June 8, 2021.

130. Liao M, et al. Single-cell landscape of bronchoalveolar immune cells in patients with COVID-19. Nat Med. 2020;26(6):842-844.

131. Trump S, et al. Hypertension delays viral clearance and exacerbates airway hyperinflammation in patients with COVID-19 [published online December 27, 2020]. Nat Biotechnol. https://doi. org/10.1038/s41587-020-00796-1.

132. Wauters E, et al. Discriminating mild from critical COVID-19 by innate and adaptive immune single-cell profiling of bronchoalveolar lavages. Cell Res. 2021;31(3):272-290.

133. Walter JM, et al. Multidimensional assessment of the host response in mechanically ventilated patients with suspected pneumonia. Am J Respir Crit Care Med. 2019;199(10):1225-1237.

134. Califano D, et al. Effects of influenza on alveolar macrophage viability are dependent on mouse genetic strain. J Immunol. 2018;201(1):134-144.

135. McQuattie-Pimentel AC, et al. The lung microenvironment shapes a dysfunctional response of alveolar macrophages in aging. J Clin Invest. 2021;131(4):e140299. 
136. Misharin AV, et al. Monocyte-derived alveolar macrophages drive lung fibrosis and persist in the lung over the life span. JExp Med. 2017;214(8):2387-2404.

137. Kim HM, et al. Alveolar macrophages are indispensable for controlling influenza viruses in lungs of pigs. J Virol. 2008;82(9):4265-4274.

138. Huang FF, et al. GM-CSF in the lung protects against lethal influenza infection. Am J Respir Crit Care Med. 2011;184(2):259-268.

139. Huang H, et al. Protective effects of recombinant human granulocyte macrophage colony stimulating factor on H1N1 influenza virus-induced pneumonia in mice. Cytokine. 2010;51(2):151-157.

140. Herold S, et al. Inhaled granulocyte/macrophage colony-stimulating factor as treatment of pneumonia-associated acute respiratory distress syndrome. Am J Respir Crit Care Med. 2014;189(5):609-611.

141. Roussel M, et al. Comparative immune profiling of acute respiratory distress syndrome patients with or without SARS-CoV2 infection. Cell Rep Med. 2021;2(6):100291.

142.Zhang F, et al. IFN- $\gamma$ and TNF- $\alpha$ drive a CXCL10+ CCL2+ macrophage phenotype expanded in severe COVID-19 lungs and inflammatory diseases with tissue inflammation. Genome Med. 2021;13(1):64.

143. Mateus J, et al. Selective and cross-reactive SARS-CoV-2 T cell epitopes in unexposed humans. Science. 2020;370(6512):89-94.

144. Braun J, et al. Presence of SARS-CoV-2 reactive $\mathrm{T}$ cells in COVID-19 patients and healthy donors [preprint]. https://doi.org/10.1101/2020.04.17.2 0061440. Posted on medRxiv April 22, 2020.

145. Dykema AG, et al. Functional characterization of CD4+ T-cell receptors cross-reactive for SARS$\mathrm{CoV}-2$ and endemic coronaviruses. J Clin Invest. 2021;131(10):e146922.

146.Anderson EM, et al. Seasonal human coronavirus antibodies are boosted upon SARS-CoV-2 infection but not associated with protection. Cell. 2021;184(7):1858-1864.

147. Herold S, et al. Lung epithelial apoptosis in influenza virus pneumonia: the role of macrophage-expressed TNF-related apoptosis-inducing ligand. J Exp Med. 2008;205(13):3065-3077.

148. Watanabe S, et al. The role of macrophages in the resolution of inflammation. JClin Invest. 2019;129(7):2619-2628.

149. Westphalen K, et al. Sessile alveolar macrophages communicate with alveolar epithelium to modulate immunity. Nature. 2014;506(7489):503-506.

150. Neupane AS, et al. Patrolling alveolar macrophages conceal bacteria from the immune system to main- tain homeostasis. Cell. 2020;183(1):110-125.

151. Chakarov S, et al. Two distinct interstitial macrophage populations coexist across tissues in specific subtissular niches. Science. 2019;363(6432):eaau0964.

152. van Kampen JJA, et al. Duration and key determinants of infectious virus shedding in hospitalized patients with coronavirus disease-2019 (COVID 19). Nat Commun. 2021;12(1):267.

153. Wölfel R, et al. Virological assessment of hospitalized patients with COVID-2019. Nature. 2020;581(7809):465-469.

154. Beigel JH, et al. Remdesivir for the treatment of Covid-19 - final report. N Engl J Med. 2020;383(19):1813-1826.

155. Wang Y, et al. Remdesivir in adults with severe COVID-19: a randomised, double-blind, placebo-controlled, multicentre trial. Lancet. 2020;395(10236):1569-1578.

156. Kalil AC, et al. Baricitinib plus remdesivir for hospitalized adults with Covid-19. N Engl J Med. 2021;384(9):795-807.

157. Chu $\mathrm{H}$, et al. Comparative replication and immune activation profiles of SARS-CoV-2 and SARS-CoV in human lungs: an ex vivo study with implications for the pathogenesis of COVID-19. Clin Infect Dis. 2020;71(6):1400-1409.

158. Grant RA, et al. Alveolitis in severe SARS-CoV-2 pneumonia is driven by self-sustaining circuits between infected alveolar macrophages and $\mathrm{T}$ cells. Nature. 2020;590(7847):635-641.

159. Muus C, et al. Integrated analyses of single-cel atlases reveal age, gender, and smoking status associations with cell type-specific expression of mediators of SARS-CoV-2 viral entry and highlights inflammatory programs in putative target cells [preprint]. https://doi. org/10.1101/2020.04.19.049254. Posted on bioRxiv April 20, 2020.

160.Zhou J, et al. Active replication of Middle East respiratory syndrome coronavirus and aberrant induction of inflammatory cytokines and chemokines in human macrophages: implications for pathogenesis. J Infect Dis. 2014;209(9):1331-1342.

161. Yip MS, et al. Antibody-dependent infection of human macrophages by severe acute respiratory syndrome coronavirus. Virol J. 2014;11:82.

162. Arvin AM, et al. A perspective on potential antibody-dependent enhancement of SARS-CoV-2. Nature. 2020;584(7821):353-363.

163. Li D, et al. The functions of SARS-CoV-2 neutralizing and infection-enhancing antibodies in vitro and in mice and nonhuman primates [preprint]. https://doi.org/10.1101/2020.12.31.424729.
Posted on bioRxiv January 2, 2021.

164. Guilliams M, et al. Division of labor between lung dendritic cells and macrophages in the defense against pulmonary infections. Mucosal Immunol. 2013;6(3):464-473

165. Jakubzick CV, et al. Monocyte differentiation and antigen-presenting functions. Nat Rev Immunol. 2017;17(6):349-362.

166. Flament H, et al. Outcome of SARS-CoV-2 infection is linked to MAIT cell activation and cytotoxicity. Nat Immunol. 2021;22(3):322-335.

167. Gioia C, et al. T-cell response profiling to biological threat agents including the SARS coronavirus. Int J Immunopathol Pharmacol. 2005;18(3):525-530.

168. Grifoni A, et al. Targets of $\mathrm{T}$ cell responses to SARS-CoV-2 Coronavirus in humans with COVID-19 disease and unexposed individuals. Cell. 2020;181(7):1489-1501.

169.Le Bert N, et al. SARS-CoV-2-specific T cell immunity in cases of COVID-19 and SARS, and uninfected controls. Nature. 2020;584(7821):457-462

170.Bacher $\mathrm{P}$, et al. Low-avidity $\mathrm{CD} 4^{+} \mathrm{T}$ cell responses to SARS-CoV-2 in unexposed individuals and humans with severe COVID-19. Immunity. 2020;53(6):1258-1271.

171. Zhang Q, et al. Inborn errors of type I IFN immunity in patients with life-threatening COVID-19. Science. 2020;370(6515):eabd4570.

172. Pairo-Castineira E, et al. Genetic mechanisms of critical illness in COVID-19. Nature. 2021;591(7848):92-98.

173. Severe Covid-19 GWAS Group, et al. Genomewide association study of severe Covid19 with respiratory failure. $N$ Engl J Med. 2020;383(16):1522-1534.

174. Wang L, et al. An atlas connecting shared genetic architecture of human diseases and molecular phenotypes provides insight into COVID-19 susceptibility [preprint]. https://doi.org/10.1101/20 20.12.20.20248572. Posted on medRxiv December 22, 2020

175. Angriman F, et al. Interleukin-6 receptor blockade in patients with COVID-19: placing clinical trials into context. Lancet Respir Med. 2021;9(6):655-664.

176. Reyfman PA, et al. Single-cell transcriptomic analysis of human lung provides insights into the pathobiology of pulmonary fibrosis. Am J Respir Crit Care Med. 2019;199(12):1517-1536.

177. Habermann AC, et al. Single-cell RNA sequencing reveals profibrotic roles of distinct epithelial and mesenchymal lineages in pulmonary fibrosis. Sci Adv. 2020;6(28):eaba1972. 